[Agr. Biol. Chem., Vol. 29, No. 8, p. 719 723, 1965]

\title{
Phytochemical Studies on the Tobacco Alkaloids
}

\section{Part IX. Question for Nornicotine as a Precursor of Nicotine}

\author{
By Shigenobu Mizusaki, Takuro KISAKI and Einosuke TamaKI \\ Central Research Institute, Japan Monopoly Corporation, 1-28-3, \\ Nishishinagawa Shinagawa-ku, Tokyo, Japan \\ Received January 18, 1965
}

\begin{abstract}
$d l$-Ornithine-2-14 $\mathrm{C}, d l$-methionine- ${ }^{14} \mathrm{CH}_{3}$ and partially racemized $l$-nornicotine-2,5-14 $\mathrm{C}$ were administered to aseptically grown excised roots ( $N$. rustica var. Brasilia). Incorporation of their radioactivity to nicotine was compared. The extent of their radioactive incorporation to nicotine was high in the order of ornithine, methionine and nornicotine; incorporation of radioactivity of nornicotine to nicotine was extraordinarily low. ${ }^{15 N-L a b e l e d}$ nornicotine was also fed to the same materials and $15 \mathrm{~N}$ distribution was examined. Most of $15 \mathrm{~N}$ still remained in the nornicotine reisolated. Marked amounts of $15 \mathrm{~N}$ were located in the ethanol-insoluble fraction, the amino acid fraction and the substances having chromatographic $R_{F}$ value close to that of nicotine. Only small amount of $15 \mathrm{~N}$ was incorporated to the isolated nicotine.

Nornicotine is generally accepted to be a direct precursor of nicotine in tobacco plants. From these findings, however, it can be said that the biosynthesis of nicotine can occur through other routes without going through nornicotine.
\end{abstract}

\section{INTRODUCTION}

After administration of nornicotine $-{ }^{15} \mathrm{~N}$ to tobacco plants, Tso and Jeffrey ${ }^{11}$ have isolated nicotine labeled with ${ }^{15} \mathrm{~N}$ from the plants, and proposed nornicotine as a precursor of nicotine. Later, they have studied the incorporation rate of ${ }^{3} \mathrm{H}$ in the tobacco alkaloids and found that the relative change of the ${ }^{3} \mathrm{H}$ specific activities of the alkaloids can best be explained on the supposition of nornicotine as a direct precursor of nicotine. ${ }^{21}$ Leete $^{3)}$ has also postulated nornicotine as a direct precursor of nicotine in his biosynthetic scheme of nicotine from ornithine.

However, our results described in the preceding paper $^{4}$ indicate that the nornicotine

1) T.C. Tso and R. N. Jeffry, Arch. Biochem. Biophys., $80,46(1959)$.

2) T.C. Tso and R. N. Jeffrey, Arch. Biochem. Biophys., 97, 4 (1962).

3) E. Leete, "Biogenesis of Natural Compounds", Pergamon Press, 1963, p. 739 .

4) S. Mizusaki, T. Kisaki and E. Tamaki, This Journa1, 29, $714(1965)$. produced in the tobacco root is biosynthesized through at least two different pathways: exclusive incorporation of $\mathrm{C}-2$ of ornithine to C-2 and equal incorporation to $\mathrm{C}-2$ and $\mathrm{C}-5$ of the pyrrolidine ring. The proposed explanation for the nornicotine having equal activities at $\mathrm{C}-2$ and $\mathrm{C}-5$ from ornithine $-2-{ }^{14} \mathrm{C}$ is that the nornicotine may be derived from nicotine by demethylation. ${ }^{5)}$ Accordingly, neither of the two biosynthetic routes can supply nornicotine which can serve as a precursor of nicotine having equal activites at $\mathrm{C}-2$ and $\mathrm{C}-5$ from ornithine- $2-{ }^{14} \mathrm{C}$. This results seem to be consistent with our previous result $s^{6,7)}$ of a series of studies of the optical properties of the tabacco alkaloids. However, the results described in the previous paper

\footnotetext{
5) S. Mizusaki, T. Kisaki and E. Tamaki, This Journal, $29,78(1965)$.

6) T. Kisaki and E. Tamaki, Arch. Biochem. Biophys., 94, 252 (1961).

7) T. Kisaki and E. Tamaki, Naturwissenschaften, 47, 541 (1960).
} 
cannot exclude a possibility by which some of the nornicotine can be synthesized from ornithine- $2-{ }^{14} \mathrm{C}$ and can be methylated to give nicotine labeled equally at C-2 and C-5. This is the biosynthetic mode which is presumed by many authors as those cited above. Hence, it is desirable to make another study to persuade whether or not nornicotine can be a direct precursor of nicotine in tabacco plants. To this end, we have examined on incorporation of the label to nicotine by feeding nornicotine $-{ }^{15} \mathrm{~N}$, nornicotine $-2,5-{ }^{14} \mathrm{C}$, ornithine $-2-{ }^{14} \mathrm{C}$ and methionine- ${ }^{14} \mathrm{CH}_{3}$ to aseptic cultures of excised roots to avoid any microbial action. It has been well known that ornithine is a good precursor of the pyrrolidine ring of nicotine, and methionine is a common methyl donor in plants and is incorporated in the methyl moiety of nicotine in tabacco plants.

\section{EXPERIMENTAL}

\section{Excised root cultures}

An aseptic culture of tobacco root (Nicotiana rustica var. Brasilia) was performed in a $100 \mathrm{ml}$ of flask containing $30 \mathrm{ml}$ of medium according to Solt's method. ${ }^{8}$ The third successive cultures of the root were used for the feeding experiment,

\section{Tracers}

$d l$-Ornithine-2-14C $(26.0 \mathrm{mc} / \mathrm{mm})$ was purchased from California Corporation for Biochemical Research. dlMethionine- ${ }^{14} \mathrm{CH}_{3}(2.3 \mathrm{mc} / \mathrm{mM})$ was purchased from Daiichi Chemical Co. Nornicotine-2,5-14C was prepared in the following way. Nicotine-2,5-14C, which was biosynthesized from ornithine- $2-14 \mathrm{C}$ by excised tobacco roots, was converted to nornicotine by feeding to excised Nicotiana tabacum "Cherry Red" grown on tomato stock. The radioactive nornicotine ${ }^{9}$ ) was purified in a same method ${ }^{10}$ as described previously; specific activity, $1.10 \times 10^{7}$ c.p.m. $/ \mathrm{mM}$. Nornicotine${ }^{15} \mathrm{~N}$ was prepared in the following way. Nicotiana glutinosa plants were grown in sand by supplying $\left({ }^{15} \mathrm{NH}_{4}\right)_{2} \mathrm{SO}_{4}\left(30 \%{ }^{15} \mathrm{~N}\right.$ atom excess) as nitrogen source. A crude alkaloid fraction extracted from the plants was fractionally distilled to give a nornicotine fraction boiling at $123^{\circ} \mathrm{C} / 6.5 \mathrm{~mm}$ and after several recry-

8) M.L. Solt, Plant Physiol., 32, 480 (1957).

9) The nordicotine obtained here is $l$-predominant norincotine.

10) T. Kisaki and B. Tamaki, This Journal, 28, 492 (1964). stallizations of the dipicrate, it melted at $187 \sim 9^{\circ} \mathrm{C}$, $[\alpha]_{D}^{24}=-71.70$. Oxidation of small portion of the nornicotine with neutral $\mathrm{KMnO}_{4}$ solution gave nicotinic acid. Upon ${ }^{15} \mathrm{~N}$ analyses, it was shown that ${ }^{15} \mathrm{~N}$ atom excess \% was 5.49 at the pyridine nitrogen and 5.67 at the pyrrolidine nitrogen.

\section{Administration of tracers}

Each culture solution of 30 flasks containing 4 weeks old tobacco roots was aseptically renewed with $20 \mathrm{ml}$ of culture solution containing either $6.51 \mathrm{mg}$ of nornicotine $-15 \mathrm{~N}$ having $5.58{ }^{15} \mathrm{~N}$ atom excess $\%$ (adjusted at $\mathrm{pH}=6.0$ with acetic acid), dl-ornithine${ }^{2-14} \mathrm{C}^{11}$, dl-methionine-14 $\mathrm{CH}_{3}$, or nornicotine-2,5-14 $\mathrm{C}$, respectively. After 2-week additional culture period the media of each flask were combined and used for the analyses.

\section{Analytical procedure}

Aseptic cultures fed with radioactive compounds were filtered through a fritted glass filter and separat. ed to roots (average fresh weight, approximately 12g) and culture fluids. After acidification with acetic acid, the culture fluids were concentrated in vacuo. The concentrate and the roots were again combined and were subjected to steam distillation on alkalinization. The steam distillate was caught in hydrochloric acid solution. According to the Brown and Barthel,12) an aliquot of the distillate was treated with sodium nitrite to nitrosofy secondary amine tobacco alkaloids and again steam distilled to separate nicotine from nornicotine. The nicotine content was determined spectrophotometrically by the U.V. method ${ }^{18)}$ and the radioactivity was determined after drying an aliquot of the distillate on a planchet. The cultures fed with nornicotine-15N were filtered through a fritted glass filter and the roots remaining on the filter were washed several times with water (fresh weight, $11.939 \mathrm{~g}$ ). The roots were then extracted repeatedly with $100 \mathrm{ml}$ of $70 \%$ ethanol containing $0.1 \%$ acetic acid. The culture media, washings and ethanol extracts were combined and concentrated to dryness in vacuo. To the concentrate, $51 \mathrm{mg}$ of nicotine and $55 \mathrm{mg}$ of nornicotine were added as carriers, respectively and, after alkalinization with ammonia, alkaloids were extracted countinuously with chloroform. The chloroform extract was liquid-chromatographed on

11) $d$-Form of ornithine appears not to be assimilated by the roots.

I2) C. V. Brown and W. F. Barthel, Ind. Eng. Chem., Anal. Ed., 15, 740 (1943).

13) C. O. Willits, M.L. Swain, J. A. Conelley and B.A. Brice, Anal. Chem. 22, 430 (1950). 

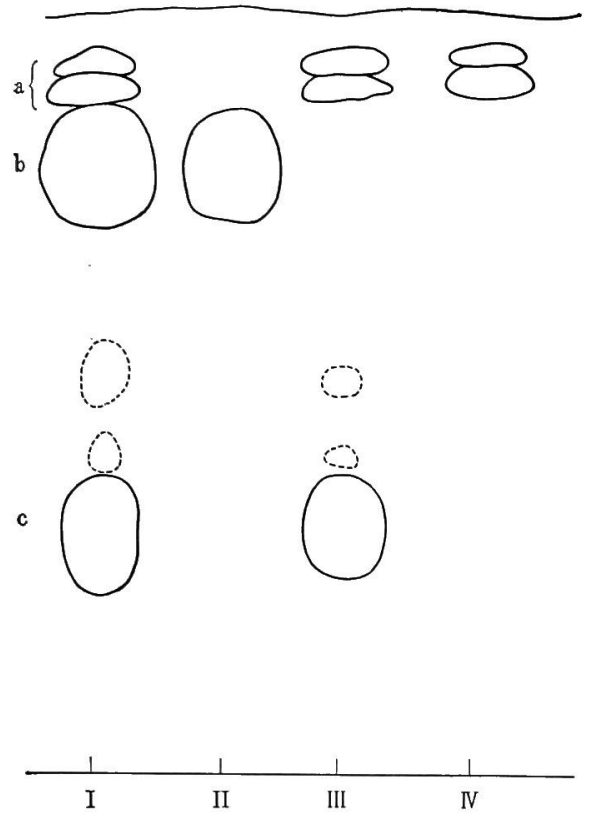

FIG. 1. Paperchromatograms of the Fractionated Alkaloids from the Excised Tobacco Root Culture.

Condition in paperchromatography is similar to that described in the preceding paper.4)

I Chloroform extract from ammoniacal aqueous solution II Ether eluate from alumina column

III $2 \%$ methanol-ether eluate from alumina column

IV Chloroform extract from $\mathrm{pH}=5$ aqueous solution

d HR fraction b Nicotine c Nornicotine

alumina column $(3 \times 20 \mathrm{~cm})$. As shown in Fig. 1, nicotine was obtained in the ether eluate, and nornicotine and two other Koenig-positive spots (HR) having high $R_{F}$ values appeared in the $2 \%$ methanolether eluate. The nicotine was further purified by repetition of recrystallization of its picrate. The $2 \%$ methanol-ether eluate was shaken with $\mathrm{N}$ hydrochloric acid and the hydrochloric acid solution was adjusted to $\mathrm{pH} 5.4 \sim 5.6$ and the substances corresponding to HR were continuously extracted with chloroform. The chloroform extract was again shaken with $\mathrm{N}$ hydrochloric acid and reextracted with chloroform at the same $\mathrm{pH}$. On three repetition of this procedure, HR was separated from nornicotine. The mother liquors were combined and, after alkalinization with $\mathrm{NaOH}$, nornicotine was extracted with chloroform. The amino acid fraction was concentrated in vacuo and treated with Dowex $50 \times 4\left(\mathrm{H}^{+}\right)$ion exchange resin. Elution of the column with $2 \mathrm{~N}$ ammonia released amino acid which had been adsorbed. Auto-

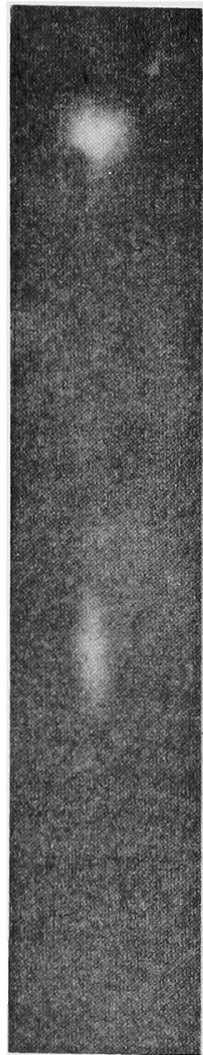

(a)

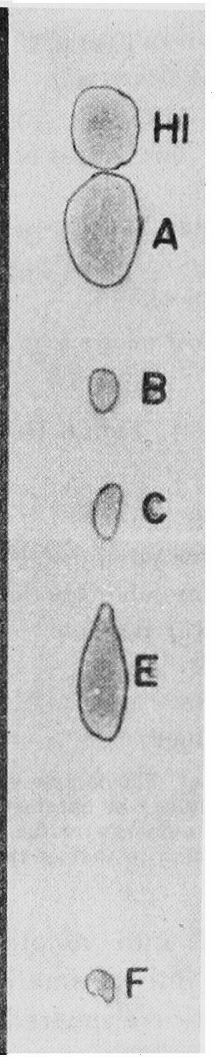

(b)
FIG. 2. Autoradiogram (a) and Parerchromatogram (b) of Alkaloid of the Sample Fed with Nornicotine-2,5-14 C.

Conditions in paperchromatography and radioautography are similar to those described in the preceding paper. ${ }^{4}$

$$
\begin{array}{ll}
\text { A. Nicotine } & \text { E. Nornicotine }
\end{array}
$$

radiography was made in the similar manner to the preceding paper. ${ }^{4}{ }^{15} \mathrm{~N}$ analysis was preformed by mass spectrometer at Institute of Physical and Chemical Research, Tokyo, Japan. Radioactive assay was made by Hitachi RDF-4 windowless gasflow GM counter.

\section{RESULTS AND DISCUSSION}

The results of radioactive incorporation to nicotine of either ornithine, methionine or nornicotine labeled with ${ }^{14} \mathrm{C}$ fed to the excised root culture are shown in Table I. dl-Ornithine-2- $-{ }^{14} \mathrm{C}$ and $d l$-methionine $-{ }^{14} \mathrm{CH}_{3}$ were in- 
TABle I. COMPARISON OF INCORPORATION ON VARIOUs PRECURSORS TO NICOTINE IN EXCISED ROOT GULTURE

\begin{tabular}{|c|c|c|c|c|c|}
\hline Tracer & $\begin{array}{l}\text { Amount } \\
\text { (c.p.m.) }\end{array}$ & $\begin{array}{l}\text { fed } \\
(\mu \mathrm{M})\end{array}$ & $\begin{array}{l}\text { Nicotine yield } \\
(\mathrm{mg})\end{array}$ & $\begin{array}{l}\text { Total activity } \\
\text { in Nicotine } \\
\text { (c.p.m.) }\end{array}$ & $\begin{array}{c}\text { Radioactive incorporation } \\
(\%)\end{array}$ \\
\hline$d l$-Ornithine-2-14 $\mathrm{C}^{*}$ & $7.94 \times 10^{5}$ & 40 & 9.6 & $4.05 \times 10^{4}$ & 5.1 \\
\hline$d l$-Methionine-14 $\mathrm{CH}_{3} *$ & $8.03 \times 10^{5}$ & 40 & 10.2 & $2.81 \times 10^{4}$ & 3.5 \\
\hline Nornicotine $-2,5-14 \mathrm{C}$ & $4.02 \times 10^{5}$ & 46 & 8.8 & $7.50 \times 10^{2}$ & 0.19 \\
\hline
\end{tabular}

* Original tracers were diluted with either cold $l$-ornithine or $l$-methionine, respectively.

TABLE II. Distribution IN VARIOUS FRACTIONS OF ${ }^{16} \mathrm{~N}$ of NoRnicotine FED TO EXCISED ROOT CULTURE

$\begin{array}{lcccc}\text { Fraction } & \mathrm{N}(\mathrm{mg}) & 15 \mathrm{~N} \text { atom excess }(\%)^{\mathrm{c})} & { }^{15} \mathrm{~N} \text { excess }(\mathrm{mg}) & \text { Incorporation }(\%)^{\mathrm{d}} \\ \text { Nornicotine administered } & 36.97 & 5.58 & 2.06 & - \\ \text { Ethanol-insoluble fraction } & 19.03 & 0.07 & 0.013 & 0.63 \\ \text { Amino acid fraction } & 9.08 & 0.39 & 0.035 & 1.7 \\ \text { Nicotine }^{\text {a) }} & 12.76 & 0.04 & 0.005 & 0.24 \\ \text { Nornicotine }^{\mathrm{l})} & 9.76 & 1.92 & 0.19 & 9.2 \\ \text { HR fraction }^{b)} & 2.29 & 1.51 & 0.035 & 1.7\end{array}$

a) The sample was diluted with corresponding carrier. b) See the text c) Atom excess (\%) value can be obtained to three places of decimals by the mass spectrometer employed but, since the last numerical value is not always reliable, it was cut off. d) Ratio of ${ }^{10} \mathrm{~N}$ excess(mg) of individual fraction to that of the originally added nornicotine.

corporated into nicotine to a large extent. However, only a small extent of radioactivity of nornicotine appeared in the nicotine. Same result was obtained in feeding experiment of either $l$ - or $d$-nornicotine- $\mathrm{U}_{-}^{3} \mathrm{H}$ to the excised root culture. ${ }^{14}$

As proposed by Leete, it is properly considered that the biosynthetic route to nicotine from ornithine would involve several steps. On the other hand, nornicotine and methionine can be considered as a direct precursor of nicotine as a methyl acceptor and a methyl donor, respectively. Since it has been accepted that methionine is a common biological methyl donor ${ }^{15)}$ in tobacco plants, it is properly thought that its utilization to nicotine cannot be low. And, if nornicotine is a precursor of nicotine, it is expected that largest incorporation of radioactivity to nicotine must be found with nornicotine feeding. However, the result in Table $I$ is inconsistent with this expectation,

14) Unpublised data.

15) B. Ladesic, Z. Devide, N. Pravdic and D. Keglevic, Arch. Biochem. Biophys., 97, 556 (1962). casting doubt about nornicotine as a direct precursor of nicotine. Fig. 2 illustrates radioautogram of alkaloid of the sample fed with nornicotine-2,5- ${ }^{14} \mathrm{C}$. A considerable amount of radioactivity was found in the substance(s) (HI) having close $R_{F}$ value to nicotine, but no radioactivity was found in nicotine(A).

In a similar experimental condition to the feeding experiment of radioactive material, the nornicotine labeled with ${ }^{15} \mathrm{~N}$ was fed to excised root culture. Table II shows a comparison of distribution of ${ }^{15} \mathrm{~N}$ of nornicotine to nicotine and to other various fractions. Only small amount of ${ }^{15} \mathrm{~N}$ was detected in the ethanol-insoluble fraction. Most of ${ }^{15} \mathrm{~N}$ was still remained in the HR fraction which has close $R_{F}$ values to that of nicotine on paperchromatogram shown in Fig. 1 and which seems to correspond to the substance having close $R_{F}$ values to nicotine in Fig. 2. The results indicate that nornicotine can be metabolically transformed to various compound, mainly to the HR fraction, but can 
scarcely be utilized to nicotine. According to the results of the comparative study by these tracer feeding experiments described in this paper, it seems to be inconceivable that nornicotine is a direct precursor of nicotine in tobacco roots.

At least, it can be said that in Nicotiana roots the biosynthesis of nicotine can occur throuth other route(s) without going through nornicotine. Therefore, at which step in the biosynthesis of nicotine methylation takes place still remains to be answered.

Acknowledgement The authors thank Miss Yoko Tanabe for her helpful co-operation in this work. 